\title{
Hemilabile Pincer-Type Hydride Complexes of Iridium
}

\author{
Aldjia Choualeb, Alan J. Lough, Dmitry G. Gusev
}

\section{Supporting Information}

${ }^{1} \mathrm{H},{ }^{13} \mathrm{C}\left\{{ }^{1} \mathrm{H}\right\},{ }^{31} \mathrm{P}\left\{{ }^{1} \mathrm{H}\right\}$ NMR spectra of PNHN ligand (pages S2, S3, S4, respectively) and of complex 2 (pages S5, S6, S7, respectively). 


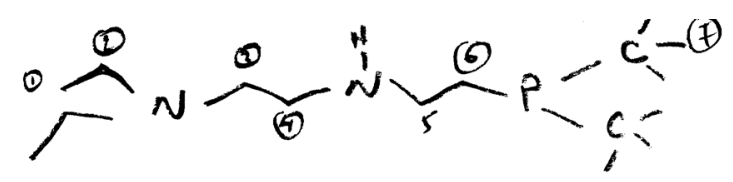

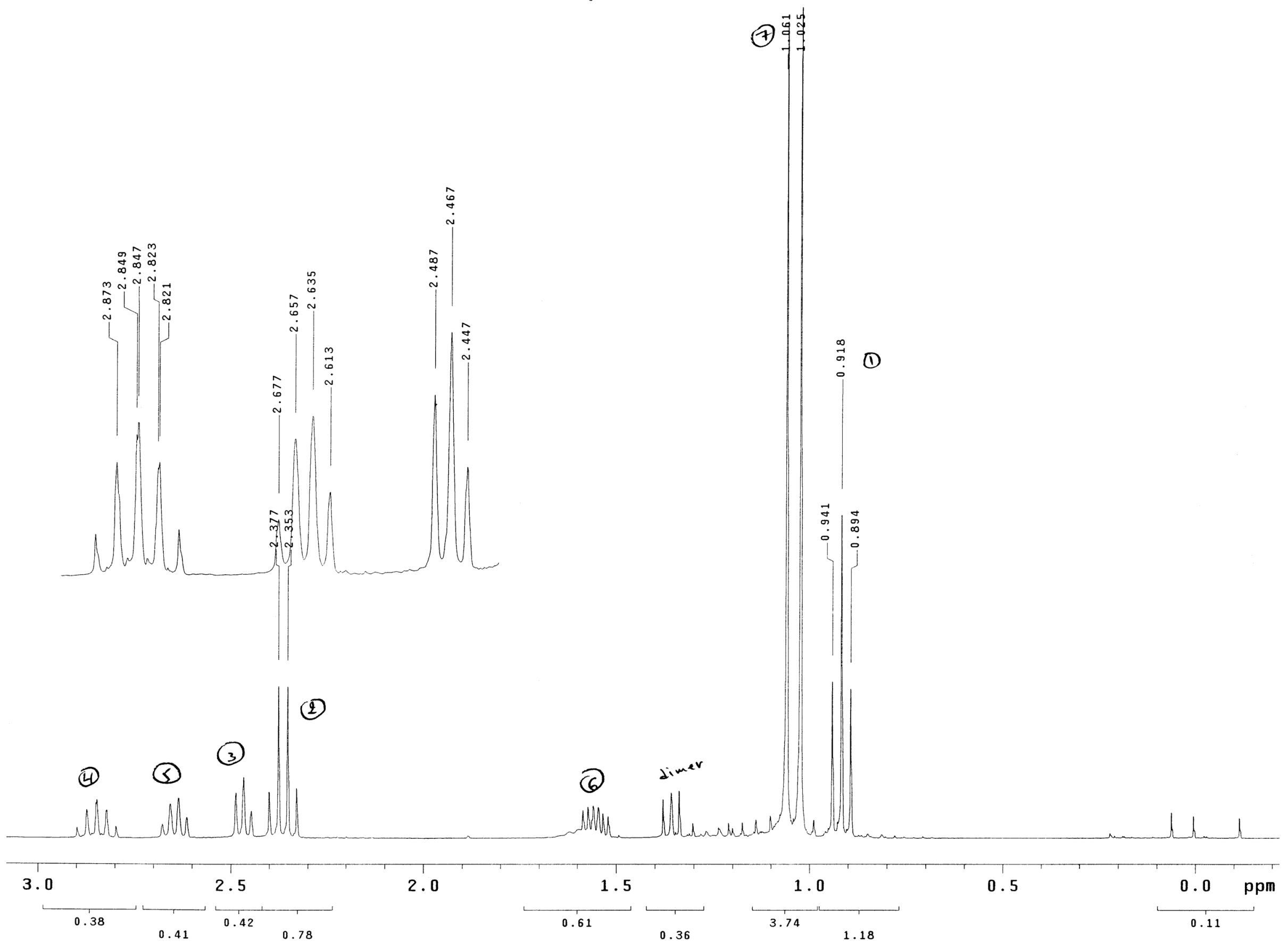




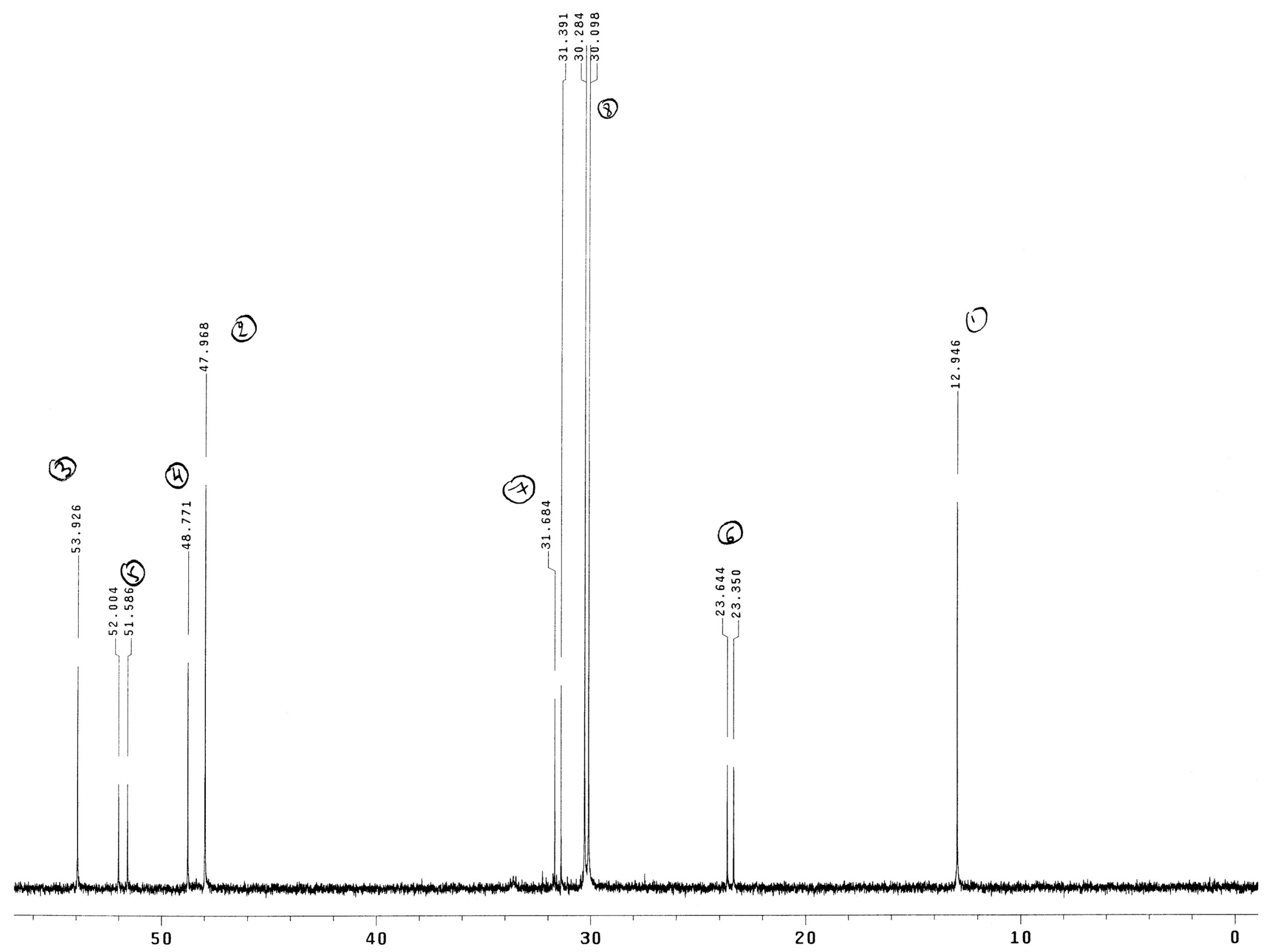




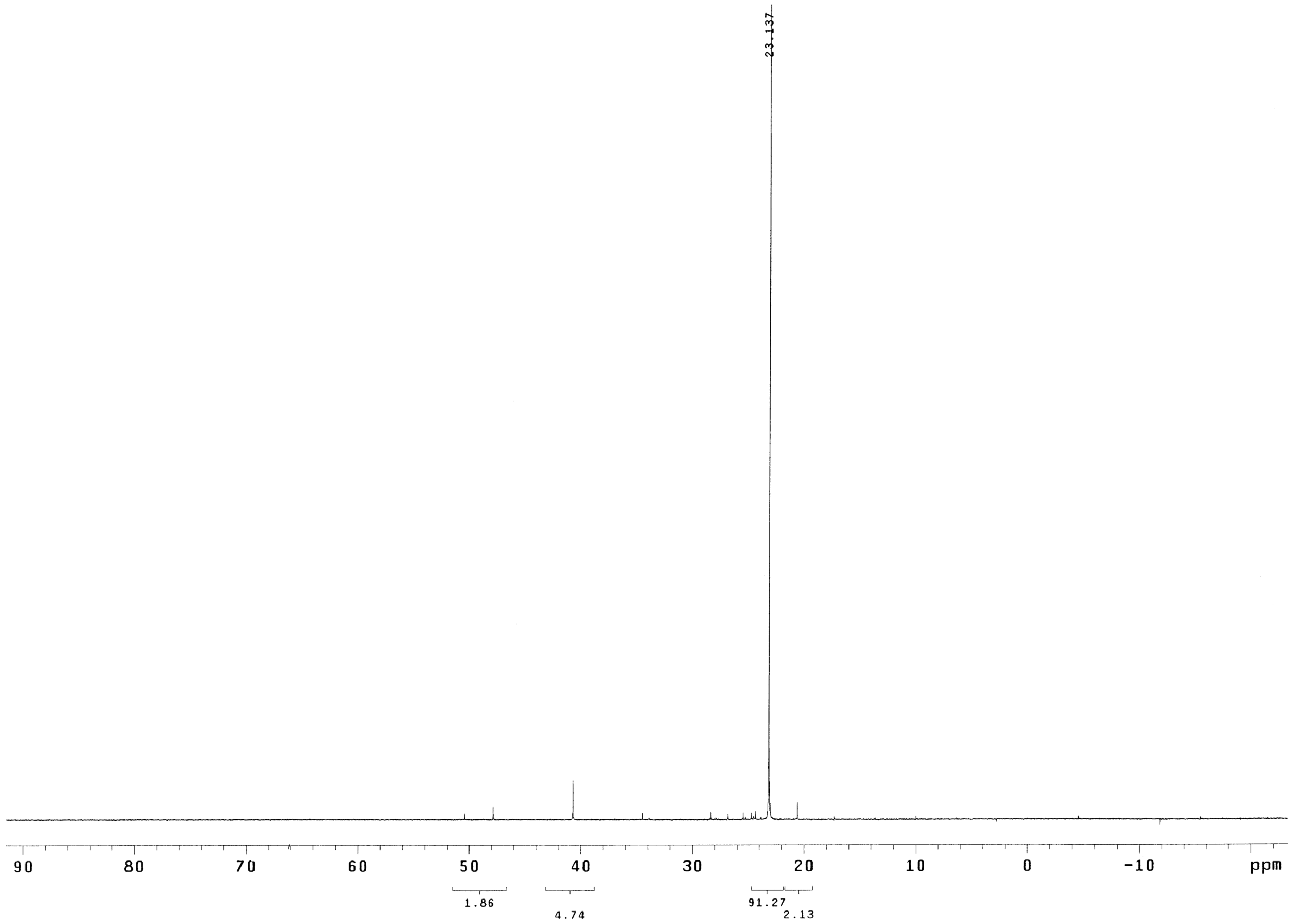




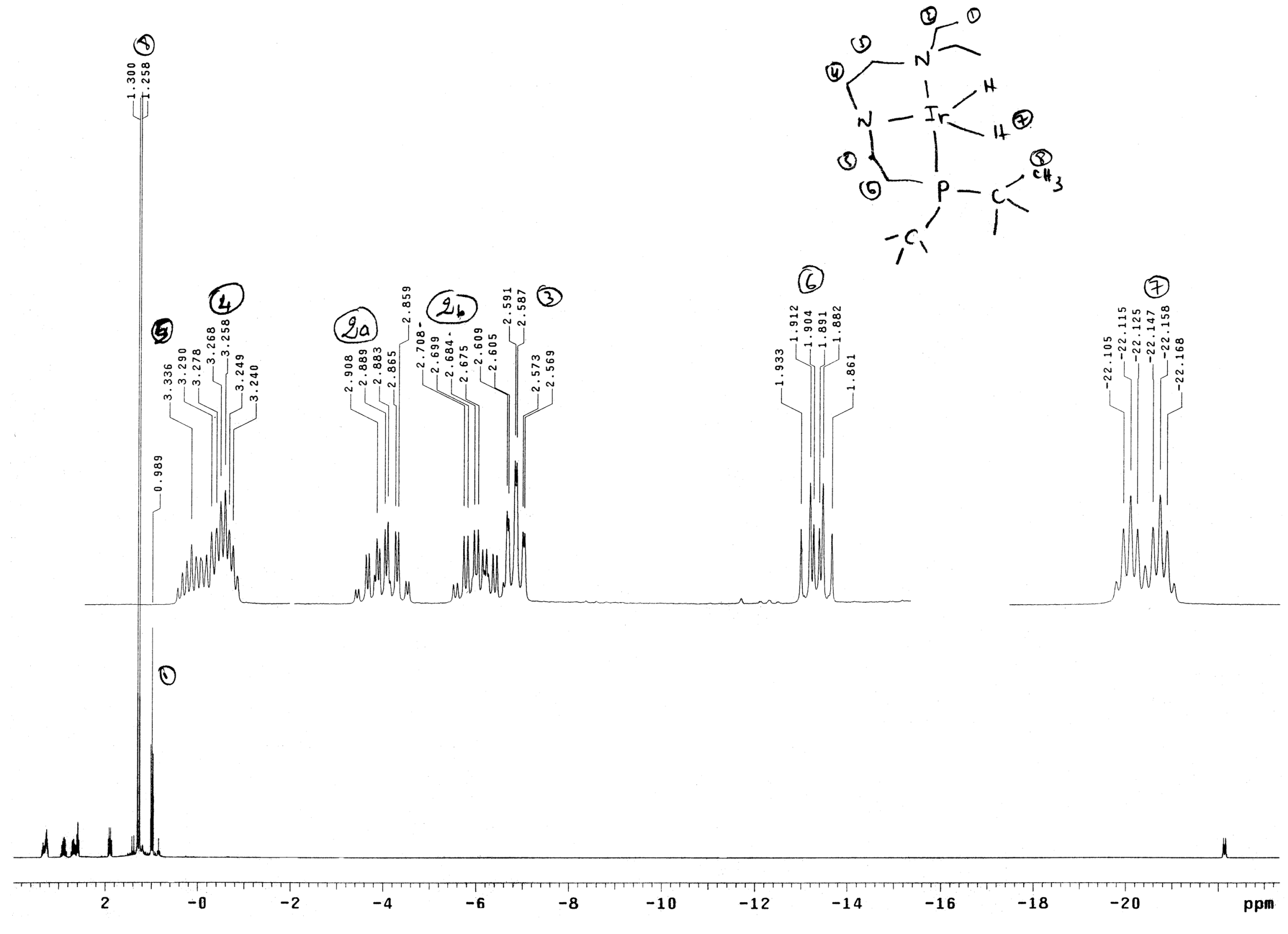




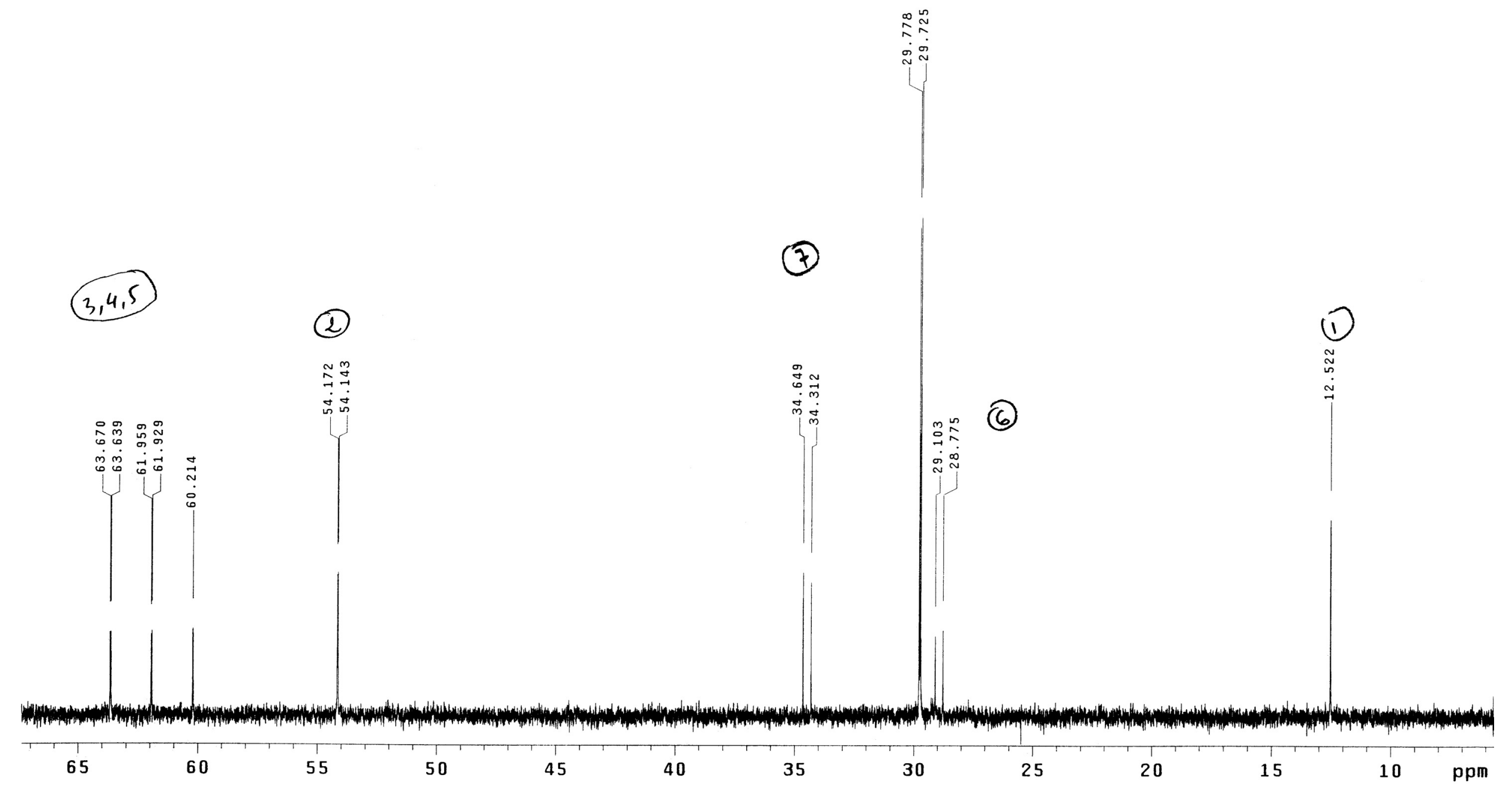




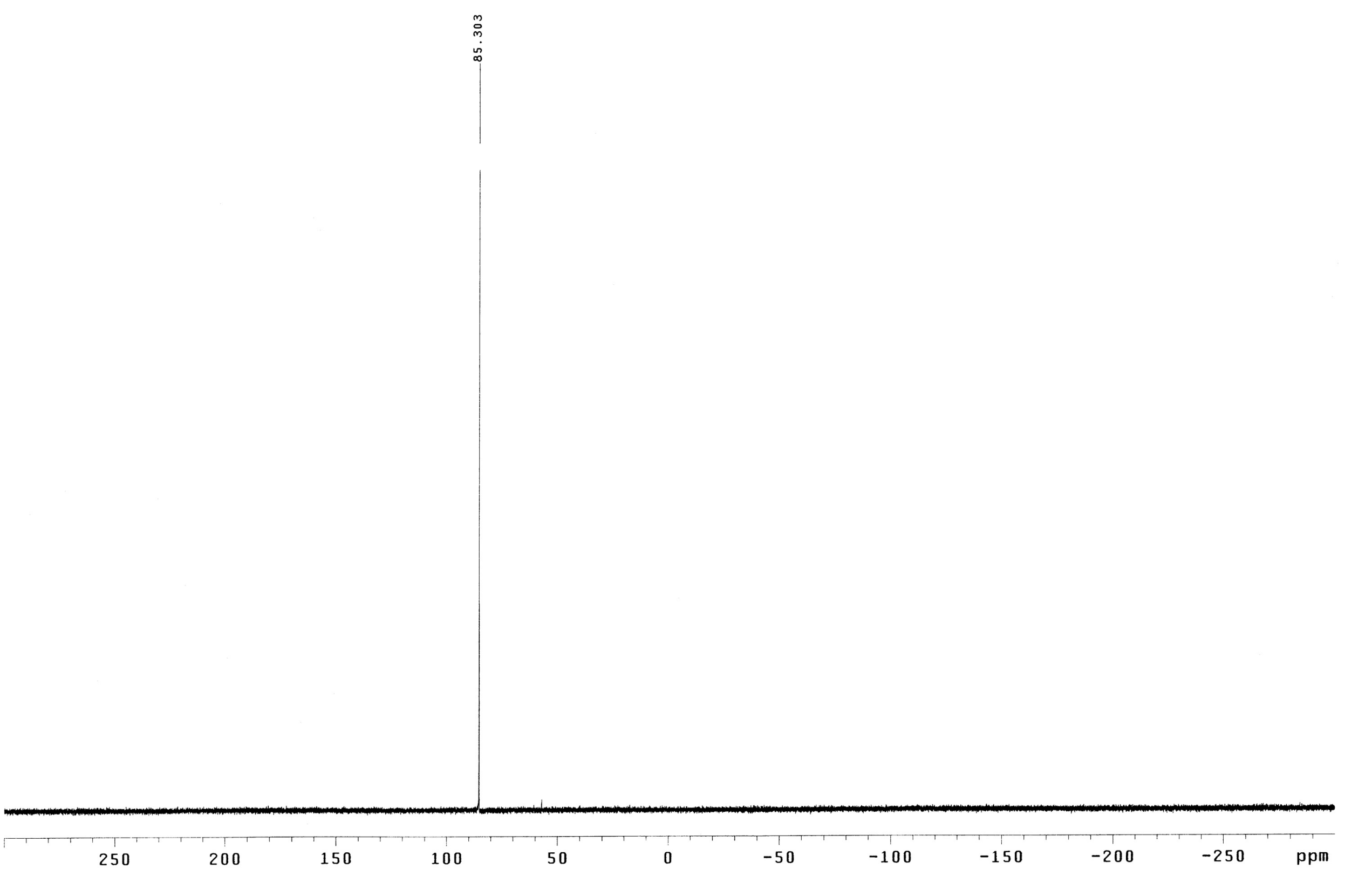

